\title{
Role of Artificial Intelligence in Social Media Marketing
}

\author{
Victoria Henry
}

\begin{abstract}
This presented review paper encompasses all the ongoing trends of the Artificial Intelligence. This review evaluates the possibilities of Artificial Intelligence (AI) in social media marketing. This review paper aims to study the potential of AI in the social media marketing. This review paper fulfils the objectives of simulation of $A I$ in the business organisations to enhance marketing which will in return increase sales. The paper aims examines the possibilities and strengths of AI. This review paper will explore the intervention of AI into marketing arena. The review flows from the general to specific. It evaluates the effect of AI on both the society as a whole and also specifically on the business organisation. It assesses the effect of AI on both the Social media and the business.
\end{abstract}

Keywords: Artificial Intelligence, Virtual Reality, Augmented reality, Marketing, business organisation, media, Social Media, Social Media Marketing, Influencer marketing.

\section{INTRODUCTION}

Siau and Yang, (2017), states that the Artificial Intelligence $(\mathrm{AI})$ is the intelligence or the power of imagination and thinking that is attributed to the machines which is otherwise not capable of imagination and thinking. The technology is progressive and Artificial Intelligence is the gift of that progressive development. The technology has gifted its Midas touch to every veins of the society. Business and its sections have also not been left behind. Technology and Artificial Intelligence has major effect on marketing (Dimitrieska, Stankovska and Efremova, 2018). The presence of Social Media and technology had already changed the statistics of marketing; with the integration of Artificial Intelligence it has taken the game a notch higher. Koseand Sert, (2017) asserts that the Artificial Intelligence has brought the new dimensions such as Slack bots, better consumer service and automated marketing. The inclusion of features likes face and voice recognition keeps the technology at par compared to the other derivatives. AI stands to be the basic necessity in the marketing. The ongoing and nascent trends of AI in social media marketing are deep learning, facial recognition, AI enabled chip, cloud storages and more engraved privacy policies. The inclusion of $\mathrm{AI}$ in the marketing strategies has revolutionised the traditional ways of marketing. The advent of Artificial Intelligence has opened ample of new opportunities and fields for further discoveries. The intervention of Artificial Intelligence in

Revised Manuscript Received on December 05, 2019.

* Correspondence Author

Ms. Victoria Henry, Research Scholar and Assistant Professor, Department of Commerce, Stella Maris College, University of Madras, Chennai, India. marketing has given rise to the scope of new researches in this topic.

\section{RESEARCH METHODOLOGY}

This review paper has considered analysing the secondary resources that are available. The journals of different organisations have been considered for evaluating the development of the AI in the marketing. The secondary sources have been considered for the review paper as they are the authentic sources that provide approximately error free data. The almost error free data aides in arriving to a strong and justifiable result and comprehension (Fletcher, 2017).

\section{A. Aims and Objectives}

This section of the paper gives the study an achievable direction. The sole aim of the study is "to understand the dynamics of the Artificial Intelligence in business and marketing". To achieve the above stated aim the study needs to establish the following objectives. These objectives will help to explore the ideas related to AI with more details and precision-

- To understand the functioning of Social Media.

- To understands the fundamental concepts of Artificial Intelligence.

- The importance of Artificial Intelligence in Social Media is to be established.

- To establish the functionality of image recognition technology in AI in the business organisation.

- To understand the contribution of Artificial Intelligence in business organisations.

- To establish the relationship of social media analytics and AI.

- To explore the potential of AI in the field of Social Media marketing.

\section{LITERATURE REVIEW}

\section{Social Media Analytics and Intelligence}

According to Stalidis, Karapistolis and Vafeiadis (2015), the advent of AI in the technology has led a revolution in the processing information. The approach towards the functioning of technology has also seen a tremendous development. With the integration of AI in the social media it has seen a positive growth. Social Media has been actively used as a medium for marketing by the organisation. 


\section{Role of Artificial Intelligence in Social Media Marketing}

The integration of AI in social media has also enhanced the analytics of the social media marketing. The integration has changed the paradigm of the marketing, the approach has transcended from being entirely traditional methods to the sophisticated digitalisation. In the present web use pattern, every consumer can be critic. The consumer behaviour and emotions become very difficult to assess through the excel sheet only. In the present trend of hash tags and emojis derivation of numerical data of concrete favouritism and oppositions are hard to find. In the current situation without the smart analytics the data that is collected by the analysts are nearly useless.

Marinchak, Forrest and Hoanca, (2018) holds the opinion that next generation AI sources its data from both structured and unstructured data. The Artificial Intelligence has made the analytics process more upgraded depending upon the current marketing trend. The integration of transformative AI into social media has helped the analytics in the understated ways-

- Transforms just insights into real data which helps the organisations to arrive at a better conclusion.

- Transformative AI also helps in analytics with judgement and concluding data as it almost thinks and works like a human.

\section{Social Media and Business Transformation}

Kane (2017) said that the social media has transformed every bit and corner of the society. The introduction of AI in technical field has proven to be a huge transformation in the corporate field. The techniques of operating the entire business process has also transformed from being manual to digital. The advent of social media, if has affected any sector in drastically is the marketing. Marketing has seen a drastic change in their technique and approach. The aide of social media has proven to be a good booster for marketing strategies. The technology is ever evolving and so is AI. There are various dimensions that have been added to the depths of AI such as virtual reality, augmented reality and other deeper level intelligence applications. The aforementioned technicalities have helped the organisations to enhance their marketing strategies. The social media has taken the transformation of business into another level. Le and et al., (2016) states that the social media can influence the business by the understated ways-

- The social media helps to transform the presence of the business from local to global. Social media helps the business to reach to a greater mass.

- The organisation through social media marketing will be able to strengthen their brand image.

- The social media increases the proximity of the organisation with the customers. The increased proximity leads to enhanced customer satisfaction.

- Social Media proves to be more cost-effective strategy for the business organisations.

\section{Impact of AI on Flourishing Business}

This part will include how AI exhibits the potential for empowering social media marketers through AI-assisted content generation, round-the-clock online presence, automated bidding, and enhanced audience targeting. The most common example of AI in the regular life is Alexa, Bixby or Siri. The artificial intelligence is more complex by the nature of it. The social media experts are hired by the organisations to filter the content and produce more customer friendly and sales generating data on the website which results in increasing the more inbound traffic and lead on the page (Fiumara and et al., 2018). It can not only enhance the modern life style but also enhance the business to flourish in the market. Theodoridis and Gkikas, (2019) opines that the integration of features like machine learning and measuring big data increases the efficiency of functioning. The introduced chat-bots in the customer service section has saved the organisations both time and money. It has enabled a quick solution to the problems. Though the chat-bots have limitations but with the evolution of the technology there is immense scope of the evolution of the customer service systems. Another major effect of AI in marketing is the lead generation that in the near future would turn into bankable sales head. The AI systems in marketing can process the data more efficiently compared to human beings. The AI system like Node helps the organisation to classify the potential leads into customers with automation software. One of the prominent organisations that use AI at best is LinkedIn which helps them to turn their leads into sales.

\section{Potential of AI assisted Social Media Marketing}

This part will include how AI exhibits the potential for empowering social media marketers through AI-assisted content generation, round-the-clock online presence, automated bidding, and enhanced audience targeting. AI has already stepped in the marketing industry and established its foot. AI stands a strong chance overpowering all other obsolete techniques. AI stands a strong chance of winning the battle against anything that is put in the competition. The AI assisted social media marketing enables and strengthens the organisation. The strong marketing strategies will enhance the sales of the organisation. The chief aim of the marketing sector is to increase sales which will be boosted with the application of AI (Fast and Horvitz, 2017). Compared to the obsolete traditional methods AI provides the organisation more enhanced method. In the open market of competition AI stands as the lone winner in increasing the potential of social media marketing through tools like virtual reality, sound and face recognition and alternative reality (Cockburn and et al., 2018). In the present marketing strategies, the interactive customisation of the products has opened a great opportunity for the customers to have an exclusive experience. Social media marketing when associated with AI stands indestructible in the path of success as both are based on the technology and technology is eve evolving. The AI along with social media will keep on enhancing and evolving in their own complex way which will prove to be the best possible confluence in the sect of marketing.

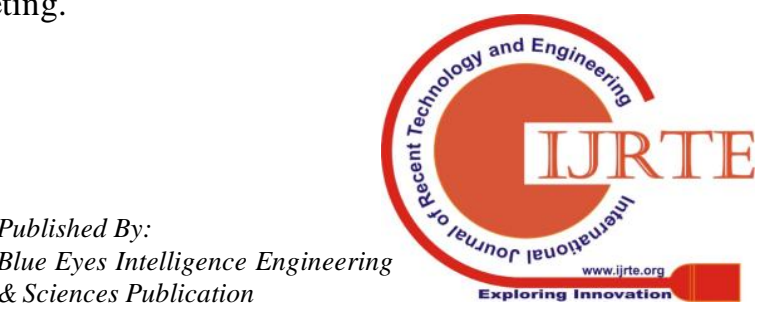




\section{Artificial Intelligence: The Present and Future of Social Media}

With the rapid expansion in technology from the last few decades, one of them is the introduction of artificial intelligence which is the demanding technology nowadays. At present, it is dominating the world and in near future humanity will totally depend on this technology. In each and every field like retail, aviation, hospitality and in-service sectors artificial intelligence has created a vast area. It has created great impact on the social media too. Due to the introduction of artificial intelligence in social media, it has helped in the growth of business. The role of social media is to connect with humans across the world. It is all about connecting with new people, sharing information and interacting with people while making the presence social also impacting each other good or bad (Zeng, Chen, Lusch, et al., 2010). Social media is a vast platform of sharing services; services offered benefits to the people and the brand also society at large. The advantages of social media are huge and artificial intelligence is playing an important role. Artificial intelligence is gaining prominence in everyday use. Many social media such as face book, twitter and instagram by implementing artificial intelligence has increased their functionality to great extent. LinkedIn is also the avid user of artificial intelligence technology and it has helped the professionals to find better opportunities for both the candidates and the employers. It has also helped to increase social media marketing to great extent. In the near future artificial intelligence will dominate the whole world. There will a time in the future when the humans will be replaced by artificial intelligence and a strong connection will be established between brands and customers (Erdoğmuş and Cicek, 2012). Artificial intelligence has created great impact in the field of Social Media.

\section{FINDINGS AND DISCUSSIONS}

Artificial Intelligence has greatly influenced the lives of the people. The complex task is easily managed in easier way and it is less costly than the traditional mode. Social media marketing saves lot of time and the operational cost is also reduced to great extent. The incorporation of $\mathrm{AI}$ in the social media analytics will enable the organisations to understand the customised need of the customers. The AI helps to understand the need to growth for the organisation in the right direction by analysing the current trend of the market. It has also helped to improve the customer service to great extent because by satisfying the needs and demands of the customer it would help the business to flourish easily. With the advancement of AI, the business organisations can reach to new heights. The technical creativity that AI brings along with its sharp sensitivity always helps the business organisation to stay ahead in the market (Aral, Dellarocas and Godes, 2013).

It is found that social media analytics is concerned with developing and evaluating informatics tools and frameworks to visualise, collect, monitor, summarise and analyse social media data obtained by specific requirements by target population. It also helps in narrowing the gap of communication between two parties. AI has flourishing effect on business and it is one of the prime reasons of the increase of sales in different retail and product companies.

Social media analytics helps the organisation to summarise and evaluate the collected data from the website and strategise the nest possible step. The introduction of AI in this whole process of data evaluation has enhanced the procedure of social media analytics. It is also found that AI has curtailed theft and errors from business. It can eliminate the tiniest of human error, theft and create risk free environment for the businesses (Müller and Bostrom, 2016). It also helps in the generation of lead as AI based systems analyse the data better from social media and understands their interest. The total business structure has changed due to the advancement of AI.

It is discovered that $\mathrm{AI}$ is dominating the present and will dominate the future in the more advanced way. It has helped in the prediction of present and future social media marketing to a great extent. It has helped to create strong bond between brands and customers. It has also helped in creating strong bond between buyers. If $\mathrm{AI}$ is used full-fledged in social media marketing it would lead to new innovation and help in growth and productivity (Hennig-Thurau, Hofacker and Bloching, 2013). In the future it will help human beings to focus on higher value analysis, decision making process and innovation. The operational cost like transportation has reduced to great extent and the whole business process is taking less time to operate with the advancement of AI. From the overall review of literature, it is found that artificial intelligence has positive effects on the development of various sectors of the economy. Social media marketing with artificial intelligence's new features have helped the social media to evolve with time.

\section{CONCLUSION}

To conclude, the emergence of artificial intelligence in social media marketing has made the business easier and flexible. Nowadays, human beings have less time to dedicate in traditional mode of marketing and entirely depend on social media to purchase the desired products. But with the introduction of AI the buying and selling of goods has become easier and the productivity also increased to great extent. Artificial intelligence is the face of the society in future and proper usage of AI would transform the world in better position in the upcoming years. Human beings would entirely depend on AI as it will be fastest way of achieving products also the dependency would increase in each and every sectors of the world.

\section{REFERENCES}

1. Agrawal, A., Gans, J.S. and Goldfarb, A., (2019). Exploring the impact of artificial intelligence: Prediction versus judgment. Information Economics and Policy.

2. Aral, S., Dellarocas, C. and Godes, D., (2013). Introduction to the special issue-social media and business transformation: a framework for research. Information Systems Research, 24(1), pp.3-13.

3. Cockburn, I.M., Henderson, R and Stern, S., (2018). The impact

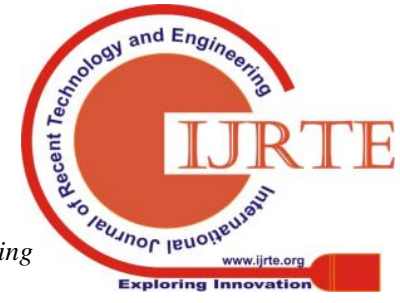




\section{Role of Artificial Intelligence in Social Media Marketing}

of artificial intelligence on innovation (No. w24449). National Bureau of Economic Research.

4. Dimitrieska, S., Stankovska, A. and Efremova, T., 2018. Artificial Intelligence and Marketing. Entrepreneurship, 6(2), pp.298-304

5. Erdoğmuş, İ.E. and Cicek, M., (2012). The impact of social media marketing on brand loyalty. Procedia-Social and Behavioral Sciences, 58, pp.1353-1360.

6. Fast, E. and Horvitz, E., (2017), February. Long-term trends in the public perception of artificial intelligence. In Thirty-First AAAI Conference on Artificial Intelligence.

7. Fiumara, G., Celesti, A., Galletta, A., Carnevale, L. and Villari, M., (2018), January. Applying Artificial Intelligence in Healthcare Social Networks to Identity Critical Issues in Patients' Posts. In healthinf (pp 680-687).

8. Fletcher, A.J., (2017). Applying critical realism in qualitative research: methodology meets method. International Journal of Social Research Methodology, 20(2), pp.181-194.

9. Hennig-Thurau, T., Hofacker, C.F. and Bloching, B., (2013). Marketing the pinball way: understanding how social media change the generation of value for consumers and companies. Journal of Interactive Marketing, 27(4), pp.237-241.

10. Kane, G.C., (2017). The evolutionary implications of social media for organizational knowledge management. Information and organization, 27(1), pp.37-46.

11. Kose, U. and Sert, S., (2017). Improving content marketing processes with the approaches by artificial intelligence. arXiv preprint arXiv: 1704.02114.

12. Le, T., Pardo, P. and Claster, W., (2016). Application of artificial neural network in social media data analysis: a case of lodging business in Philadelphia. In Artificial Neural Network Modelling (pp. 369-376). Springer, Cham.

13. Marinchak, C.L.M., Forrest, E. and Hoanca, B., (2018). The impact of artificial intelligence and virtual personal assistants on marketing. In Encyclopedia of Information Science and Technology, Fourth Edition (pp. 5748-5756). IGI global.

14. Müller, V.C. and Bostrom, N., (2016). Future progress in artificial intelligence: A survey of expert opinion. In Fundamental issues of artificial intelligence (pp. 555-572). Springer, Cham.

15. Siau, K. and Yang, Y., (2017), May. Impact of artificial intelligence, robotics, and machine learning on sales and marketing. In Twelve Annual Midwest Association for Information Systems Conference (MWAIS 2017) (pp. 18-19).

16. Stalidis, G., Karapistolis, D. and Vafeiadis, A., (2015). Marketing decision support using Artificial Intelligence and Knowledge Modeling: application to tourist destination management. Procedia-Social and Behavioral Sciences, 175, pp.106-113.

17. Theodoridis, P.K. and Gkikas, D.C., (2019). How Artificial Intelligence Affects Digital Marketing. In Strategic Innovative Marketing and Tourism (pp. 1319-1327). Springer, Cham.

18. Zeng, D., Chen, H., Lusch, R. and Li, S.H., (2010). Social media analytics and intelligence. IEEE Intelligent Systems, 25(6), pp.13-16.

\section{AUTHOR PROFILE}

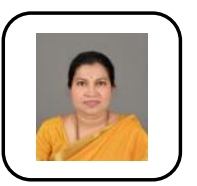

Ms. Victoria Henry, M.Com., M.Phil., NET, MBA, is an Assistant Professor from the Department of Commerce, Stella Maris College, Chennai - 600 086, that is affiliated to the University of Madras, Chennai, Tamil Nadu. My academic specialization is Marketing and Management. I am a highly spiritual person, tech savvy, with high achievement orientation, dedicated and very accommodative to changes. Aspiring to be a good leader. Currently pursuing my research in the field of Marketing, giving emphasis to millennials. Have published research papers in the fields of Digital Marketing, Social Media Marketing, Demonetisation - A catalyst to financial inclusion in India, to name a few. Have been in the field of enlightening young minds for the last 17 years. Committed towards excellence in teaching and mentoring students. My other significant contributions have come forth in the form of planning, organizing and executing meticulously varied aspects related to my profession and workplace. 